\title{
NGHIÊN CỨU CHỈ SỐ MÕ̃ CƠ THỂ VÀ MÕ̃ NỘI TẠNG TRÊN ĐỐI TƯỢNG NŨ ĂN CHAY TRƯỜNG
}

Nguyễn Hải Thủy, Võ Hoàng Lâm, Ngô Thị Minh Thảo Truờng Đại học Y Dược Huế

\section{ABSTRACT \\ Effects of vegetarian diet on body fat percentage and viceral fat level}

Body fat percentage (BFP) and visceral fat level (VFL) was considered to be the anthropometric indices and equivalent to BMI, waist circumference, but there has not been much study on people had vegetarian diet. The objectives are to evaluate the BFP, VFL and to identify the relation of long-time vegetarian, risk factor and BFP, VFL on women had vegetarian diet. Method: 239 females (age 45-55 years) had vegetarian and 239 non-vegetarian women (age 45-55 years) were control group. Result: For vegetarian, there was $82.0 \%$ on the slightly high-high BFP, while the figure for slightly high-high VFL was $28,0 \%$. The risk of increase BFP, VFL in vegetarian group compared to nonvegetarian women were 1.60 and 1.50 respectively. There were correlation between long-time vegetarian and BFP $(\mathrm{r}=0.437)$, and between long-time vegetarian and VFL $(\mathrm{r}=0.625)$. The time $>8$ year was related elevating BFP and > 20 year was related raising VFL. In term of waist $\geq 80 \mathrm{~cm}$, there were related $\mathrm{BFP}>26.5 \%$ (Se: $90.5 \%, \mathrm{Sp}$ : $72.8 \%$ ) and VFL $>9$ (Se: $92.4 \%$, Sp: $81.0 \%$ ).

\section{TÓM TẮT}

Ăn chay là chế độ ăn không có chứa mỡ và protid động vật, trong đó chế độ ăn thuần chay (vegan) có hiệu quả trên rối loạn lipid máu qua một số nghiên cứu trong và ngoài nước. Tuy vậy ảnh hưởng của thể loại ăn chay này trên tình trạng béo phì đang có nhiều tranh luận Vì vậy chúng tôi sử dụng 2 chỉ số tỉ lệ mỡ cơ thể (BFP) và mức mỡ nội tạng (VFL) để khảo sát trên đối tượng nữ ăn chay trường. Đối tượng và phương pháp: Nghiên cứu mô tả cắt ngang trên 239 phụ nữ có chế độ ăn chay trường và 239 phụ nữ không ăn chay bằng máy máy trở kháng sinh học Omron loại HBF-362. Kết quả: Nguy cơ tăng BFP, VFL ở nhóm ăn chay trường cao gấp 1,60 và 1,55 lần so với nhóm không ăn chay. Thời gian ăn chay (TGAC) tương quan thuận với chỉ số $B F P$ và VFL. Nguy cơ tăng BFP tại điểm cắt $\mathrm{TGAC}>9$ năm, nguy cơ tăng $\mathrm{VFL}$ tại điểm cắt $\mathrm{TGAC}>20$ năm. Điểm cắt $\mathrm{BFP}$ $>26,5 \%$ (Se: $90,5 \%, \mathrm{Sp}: 72,8 \%$ ) và $\mathrm{VFL}>9$ (Se: $92,4 \%, \mathrm{Sp}: 81,0 \%$ ) có liên quan đến $\mathrm{VB} \geq 80 \mathrm{~cm}$. Kết luận: Ở phụ nữ ăn chay trường có nguy cơ tăng BFP, VFL cao so với nhóm không ăn chay. Có sự tương quan thuận giữa thời gian ăn chayvới $\mathrm{BFP}$ và $\mathrm{VFL}$.

Tù khóa: Chỉ số mõ cơ thể, mưc mõ nội tạng, ăn chay.

Chịu trách nhiệm chính: Nguyễn Hải Thủy

Ngày nhận bài: 15/11/2019

Ngày phản biện khoa học: 20/12/2019

Ngày duyệt bài: 31/12/2019

\section{1. ĐẶT VẤN ĐỀ}

Béo phì là tình trạng tích lũy quá nhiều và bất thường của lipid trong các tổ chức mỡ. Béo phì đứng hàng đầu trong nhóm "các bệnh của nền văn minh", khi bị béo phì có thể làm gia tăng các bệnh lý tim mạch, bệnh lý chuyển hóa và nội tiết... Béo phì là bệnh thường gặp nhất và có tính chất toàn cầu có liên quan đến chế độ ăn, tỷ lệ bệnh và tần suất bệnh đang gia tăng rất rõ. Hiện nay, Tổ chức Y tế xem thừa cân - béo phì là một nạn dịch toàn cầu[8]. Dựa vào vị trí phân bố, mỡ được chia làm ba loại bao gồm mỡ cơ thể, mỡ nội tạng, mỡ dưới da. Mỡ nội tạng được định nghĩa là phần mô mỡ ở bụng và các cơ quan quan trọng xung quanh. Mỡ nội tạng quá cao được coi là nguyên nhân trực tiếp làm tăng lượng mỡ trong máu dẫn đến nguy cơ mắc các bệnh như: cholesterol máu cao, bệnh tim, tiểu đường typ 2[6]. 
Tích tụ mỡ nội tạng liên quan đến không chỉ cho sự phát triển của nguy cơ tim mạch, mà còn liên quan trực tiếp đến sự phát triển của bệnh tim mạch. Nghiên cứu của Matsuzawa Y và cộng sự vào năm 2012 đã chứng minh rằng béo phì nội tạng có liên quan đến bệnh lý động mạch vành ngay cả ở những người béo phì nhẹ. Tích tụ mỡ nội tạng cũng liên quan đến nhiều bệnh lý nguy hiểm khác như: Rối loạn chức năng tim, hội chứng ngưng thở khi ngủ, hội chứng chuyển hóa... Từ kết quả nghiên cứu, tác giả đã kết luận được sự tích lũy chất béo nội tạng là một nguy cơ chính của bệnh tim mạch cũng như các bệnh lý chuyển hóa[7].

Hiện nay, đã có nhiều nghiên cứu trên thế giới và trong nước chú ý đến tỉ lệ mỡ cơ thể (BFP) và mức mỡ nội tạng (VFL). Mỡ cơ thể và mức mõ̃ nội tạng được xem như những chỉ số nhân trắc tương đương với chỉ số $\mathrm{BMI}$ và vòng bụng trong đánh giá một số yếu tố nguy cơ, đặc biệt là hội chứng chuyển hóa và tim mạch. Có thể xác định các chỉ số mỡ theo nhiều cách khác nhau như: Phương pháp đo độ dày nếp gấp da bằng thước compa, phương pháp nhân trắc, phương pháp DEXA hấp thụ năng lượng kép... nhưng phương pháp phân tích trở kháng điện sinh học vẫn được sử dụng nhiều nhất bởi độ chính xác cao, giá thành rẻ, dễ sử dụng, không gây hại và có thể lặp lại nhiều lần [6].

Hiện nay, chế độ tiết thực ăn chay có khuynh hướng phổ biến với nhiều lý do trong đó có mục đích phục vụ sức khỏe. Vậy ở những người có chế độ ăn chay lâu năm thì chỉ số tỉ lệ mỡ cơ thể và mức mỡ nội tạng như thế nào. Hiện nay, chưa có nhiều nghiên cứu về chỉ số tỉ lệ mỡ cơ thể và mức mỡ nội tạng ở những người có chế độ ăn chay. Do đó chúng tôi tiến hành nghiên cứu đề tài "Nghiên cưu ảnh hương của chế độ ăn chay trương trên chỉ số mõ co thể và mõ nội tạng" với các mục tiêu:

1. Nghiên cứu chỉ số tỉ lệ mõ co thể, mõ nội tạng ở phụ nũ ăn chay truờng.

2. Khảo sát mối tuoong quan giũa thời gian ăn chay với chi số mõ cơ thể, mõ nội tạng ở phu nũ ăn chay truòng.

\section{2. ĐỐI TƯợNG VÀ PHƯƠNG PHÁP NGHIÊN CÚU}

Nghiên cứu thực hiện trên 239 phụ nữ tuổi từ 45-55 có chế độ ăn chay trường tại các chùa trên địa bàn tỉnh Thừa Thiên Huế và nhóm chứng gồm 239 phụ nữ không ăn chay từ 45-55 tuổi trên địa bàn tỉnh Thừa Thiên Huế. Từ tháng 01/2018-06/2019.

\section{1. Đối tượng}

1.1. Tiêu chuẩn chọn: Nhóm nghiên cứu:

- Phụ nữ có chế độ ăn chay trường. Thời gian ăn chay tối thiểu $>1$ năm.

- Tuổi 45 đến 55 tuổi. Đồng ý tham gia nghiên cứu.

Nhóm chứng:

- Phụ nữ có chế độ ăn bình thường. Tuổi 45 đến 55 tuổi. Đồng ý tham gia nghiên cứu.

\subsection{Tiêu chuẩn loại trù̀}

Những đối tượng đang có bệnh lý nhiễm khuẩn, phù đang điều trị với thuốc corticoid, thuốc lợi tiểu. Hoạt động thể lực nặng. Đang mang thai. Rối loạn tâm thần.

\section{Phương pháp nghiên cứu:}

2.1. Thiết kế nghiên cúu: Nghiên cứu mô tả cắt ngang có đối chứng.

2.2. Thò̀i gian và địa điểm nghiên cúu: Tháng 01/2018 - 06/2019 trên địa bàn tỉnh Thừa Thiên Huế.

2.3. Cách chọn mẫu: Nhóm nghiên cứu chọn mẫu toàn bộ, tất cả đối tượng đủ tiêu chuẩn chọn ở các chùa. Cỡ mẫu $n=239$. Nhóm chứng chọn mẫu ngẫu nhiên đơn, tỉ lệ nhóm nghiên cứu /nhóm chứng là $1 / 1$. Vậy cỡ mẫu nhóm chứng $\mathrm{n}=239$.

\subsection{Các bước tiến hành:}

2.4.1. Phuơng tiện nghiên cúu: Phiếu điều tra, ống nghe tim phổi, găng vô khuẩn, máy đo huyết áp, máy kháng định sinh học Omron loại HBF-362, thước dây.

2.4.2. Tiến hành nghiên cưu: Phỏng vấn đối tượng theo phiếu điều tra: Hỏi tiền sử, bệnh sử, đo vòng bụng, đo huyết áp, chiều cao, đo chỉ số tỷ lệ mỡ cơ thể (BFP), đo mức mỡ nội tạng (VFL), khám lâm sàng,

Cách đo các chỉ số BFP, VFL: Nhập dữ liệu tuổi, giới, chiều cao. Khi màn hình hiển thị $0,0 \mathrm{~kg}$, bước cả hai chân lên hai điện cực đồng thời hai tay nắm vào hai điện cực theo 
các rãnh dọc theo điện cực. Thời điểm đo: 7 8 giờ sáng. Tư thế đo: Đầu, lưng, hai đầu gối thẳng, hai tay nắm chặt, cánh tay thẳng tạo góc $90^{\circ}$ với cơ thể, giữ nguyên tư thế đó trong 5 giây. Máy tự động hiện thị các thông số cân nặng, BFP, VFL, BMI. Việc đo hoàn tất, mời đối tượng bước xuống khỏi điện cực, cân tự động tắt nguồn[3].

Đối tượng cần nghỉ ngơi 5-10 phút trước khi đo chỉ số BFP,VFL. Đối tượng trước đó không sử dụng chất kích thích, bia rượu, không uống nhiều nước, không tắm, không sốt hoặc cảm lạnh[1].
Tiêu chí: Ăn chay trường: Không ăn thực phẩm từ thịt cũng như các sản phẩm từ động vật. Việc ăn chay kéo dài liên tục, không bị xen kẽ với những bữa ăn mặn

Giá trị $\mathrm{BFP}$ ở nữ giới: Thấp - bình thường: <30\%; Cao nhẹ: 30 - <35\%; Cao: $\geq 35 \%$ [5]. Giá trị VFL theo Hội béo phì Nhật Bản ở nữ giới: Thấp-bình thường: 1-9; Cao nhẹ: 10-14; Cao: $\geq 15[1]$.

3. Xử lý số liệu: Số liệu nghiên cứu được xử lý và phân tích bằng chương phần mềm Medcalc, Excel 2017 với độ tin cậy tối thiểu $95 \%, \alpha<0,05$.

\section{KẾT QUẢ NGHIÊN CÚU}

\begin{tabular}{|c|c|c|c|c|c|}
\hline \multicolumn{6}{|c|}{ Bảng 1. Đặc điêm chung } \\
\hline \multicolumn{2}{|c|}{ Đặc điểm chung } & $\begin{array}{l}\text { Nhóm ăn chay } \\
\quad(n=239)\end{array}$ & Tỷ lệ & $\begin{array}{l}\text { Nhóm chứng } \\
\quad(n=239)\end{array}$ & Tỷ lệ \\
\hline \multirow[t]{2}{*}{ BMI } & $\geq 23 \mathrm{~kg} / \mathrm{m}^{2}$ & 62 & 25,9 & 68 & 28,5 \\
\hline & $<23 \mathrm{~kg} / \mathrm{m}^{2}$ & 177 & 74,1 & 171 & 71,5 \\
\hline \multirow[t]{2}{*}{ Vòng bụng } & $\geq 80 \mathrm{~cm}$ & 147 & 61,5 & 125 & 52,3 \\
\hline & $<80 \mathrm{~cm}$ & 92 & 38,5 & 114 & 47,7 \\
\hline \multirow[t]{2}{*}{ HA } & $\geq 140 / 90$ & 25 & 10,5 & 46 & 19,3 \\
\hline & $<140 / 90$ & 214 & 89,5 & 193 & 80,7 \\
\hline
\end{tabular}

Nhóm $B M I \geq 23 \mathrm{~kg} / \mathrm{m}^{2}$ là $25,9 \%$ và $\mathrm{BMI}<23 \mathrm{~kg} / \mathrm{m}^{2}$ là $74,1 \%$. Nhóm có mức huyết áp $<140 / 90$ chiếm $89,5 \%$. Tỷ lệ $\mathrm{VB} \geq 80 \mathrm{~cm}$ chiếm $61,5 \%$ và $<80 \mathrm{~cm}$ tỷ lệ $38,5 \%$.

Bảng 2. Phân bố tỷ lệ mỡ cơ thể

\begin{tabular}{|c|c|c|c|c|c|c|}
\hline \multirow{2}{*}{$\begin{array}{l}\text { Nhóm } \\
\text { đối tượng }\end{array}$} & \multicolumn{2}{|c|}{$\begin{array}{c}\text { Bình thường } \\
(20-<30 \%)\end{array}$} & \multicolumn{2}{|c|}{$\begin{array}{c}\text { Cao nhẹ - Cao } \\
(\geq \mathbf{3 0} \%)\end{array}$} & \multicolumn{2}{|c|}{ Tổng } \\
\hline & $\mathbf{n}$ & $\%$ & $\mathbf{n}$ & $\%$ & $\mathbf{n}$ & $\%$ \\
\hline Có ăn chay & 43 & 18,0 & 196 & 82,0 & 239 & 100 \\
\hline Không ăn chay & 62 & 26,0 & 177 & 74,0 & 239 & 100 \\
\hline \multicolumn{7}{|c|}{$\mathrm{OR}=1,60 ; 95 \% \mathrm{CI}: 1,03-2,47 ; \mathrm{P}=0,03$} \\
\hline
\end{tabular}

Ở nhóm phụ nữ ăn chay tỉ lệ BFP cao nhẹ - cao chiếm 82,0\% nhóm phụ nữ không ăn chay tỉ lệ $\mathrm{BFP}$ cao nhẹ - cao chiếm $74,0 \%$ với $\mathrm{OR}=1,60 ; 95 \% \mathrm{CI}$ : $1,03-2,47$, sự khác biệt có ý nghĩa thống kê với $\mathrm{p}<0,05$.

Bảng 3. Phân bố tỷ lệ mõ nội tạng

\begin{tabular}{|c|c|c|c|c|c|c|}
\hline \multirow{2}{*}{$\begin{array}{l}\text { Nhóm } \\
\text { dối tượng }\end{array}$} & \multicolumn{2}{|c|}{$\begin{array}{c}\text { Bình thường } \\
(\mathbf{1 - 9})\end{array}$} & \multicolumn{2}{c|}{$\begin{array}{c}\text { Cao nhẹ - Cao } \\
(\geq \mathbf{1 0})\end{array}$} & \multicolumn{2}{c|}{ Tổng } \\
\hline Cón chay & $\mathbf{n}$ & $\mathbf{\%}$ & $\mathbf{n}$ & $\mathbf{\%}$ & $\mathbf{n}$ & \% \\
\hline Không ăn chay & 172 & 72,0 & 67 & 28,0 & 239 & 100 \\
\hline & 191 & 80,0 & 48 & 20,0 & 239 & 100 \\
\hline
\end{tabular}

Ở nhóm phụ nữ ăn chay tỉ lệ VFL cao nhẹ - cao chiếm 28,0\% nhóm phụ nữ không ăn chay tỉ 
lệ VFL cao nhẹ cao nhẹ - cao chiếm 20,0\% với OR = 1,55; 95\% CI: 1,01 - 2,37, sự khác biệt có ý nghĩa thống kê với $\mathrm{p}<0,05$.

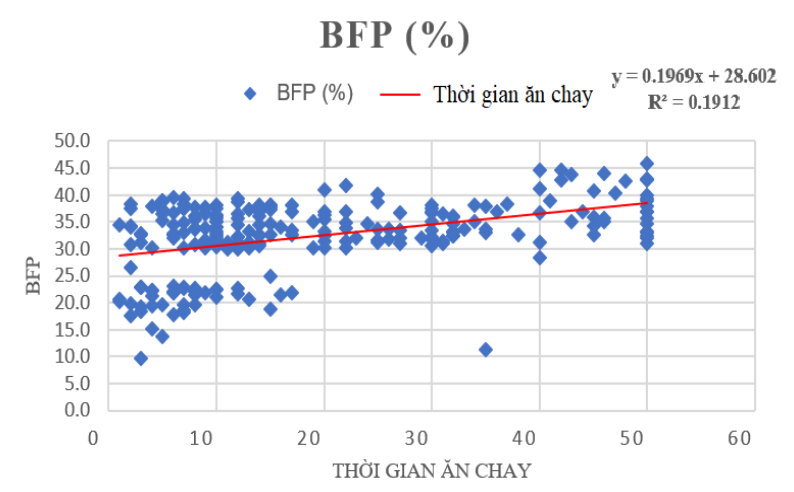

Biểu đồ 1. Tương quan giữa BFP và thời gian ăn chay

Có sự tương quan thuận trung bình giữa BFP với thời gian ăn chay, với phương trình hồi quy tuyến tính là $\mathrm{y}=0,1969 \mathrm{x}+28,602$ và hệ số tương quan $\mathrm{r}=0,437$, sự khác biệt có ý nghĩa thống kê với $\mathrm{p}<0,05$.

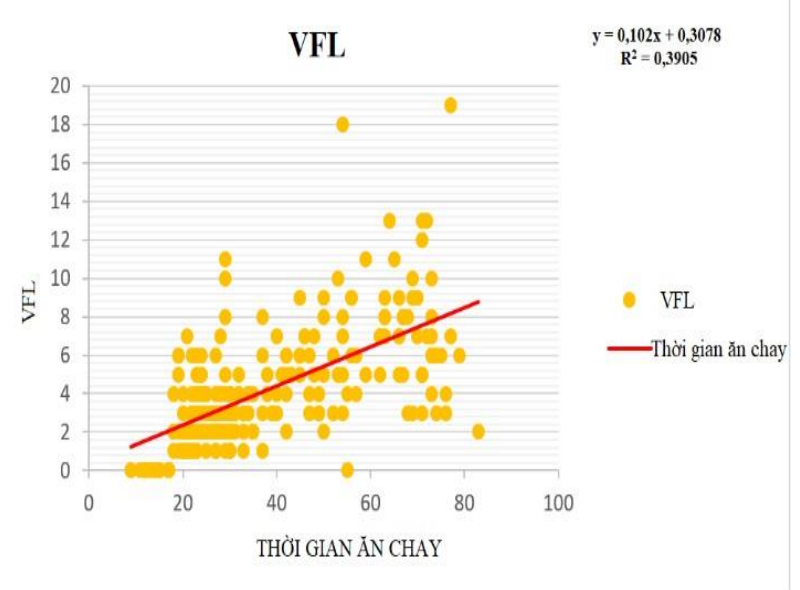

Biểu đồ 2. Tương gian giũa VFL và thời gian ăn chay

Có sự tương quan thuận trung bình giữa VFL với thời gian ăn chay, với phương trình hồi quy tuyến tính là $\mathrm{y}=0,102 \mathrm{x}+0,3078$ và hệ số tương quan $\mathrm{r}=0,625(\mathrm{p}<0,05)$.

Bảng 4. Tương quan hồi quy đa biến giữa BFP, VFL với thời gian ăn chay

\begin{tabular}{|c|c|c|c|c|}
\hline Chỉ số & B & B hiệu chỉnh & n & p \\
\hline Hằng số & $-5,664$ & & & \\
\hline BFP & 0,282 & 0,069 & 4,031 & 0,0001 \\
\hline VFL & 2,443 & 0,092 & 26,640 & $<0,0001$ \\
\hline
\end{tabular}

Qua khảo sát hồi quy đa biến số với thời gian ăn chay là biến phụ thuộc, BFP, VFL là biến độc lập có ý nghĩa thống kê chúng tôi xây dựng phương trình hồi quy tuyến tính đa biến sau:

\section{TGAC $=-5,664+0,282 * B F P+2,443 * V F L$}




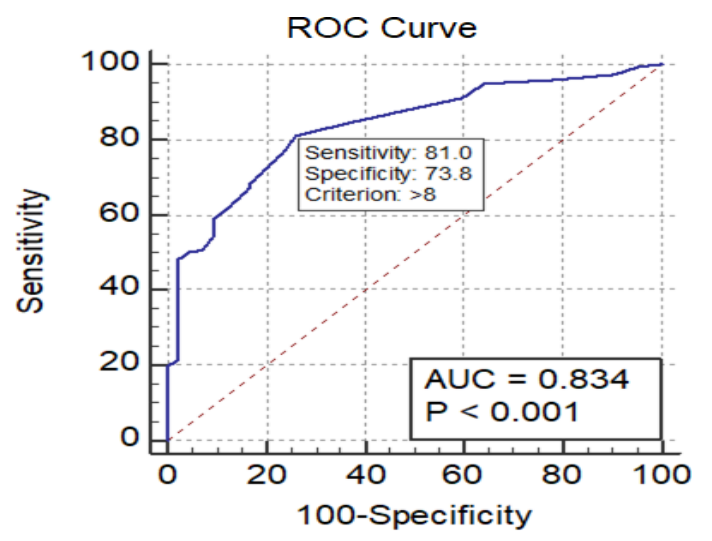

Biểu đồ 3. Biểu đồ ROC của thời gian với tăng tỷ lệ mõ cơ thể

Thời gian ăn chay có liên quan đến việc dự đoán tăng $\mathrm{BFP}$ với $\mathrm{p}<0,05$ và diện tích dưới đường cong là $83,4 \%$, tại điểm cắt trên 8 năm với độ nhạy $81,0 \%$, độ đặc hiệu $73,8 \%$.

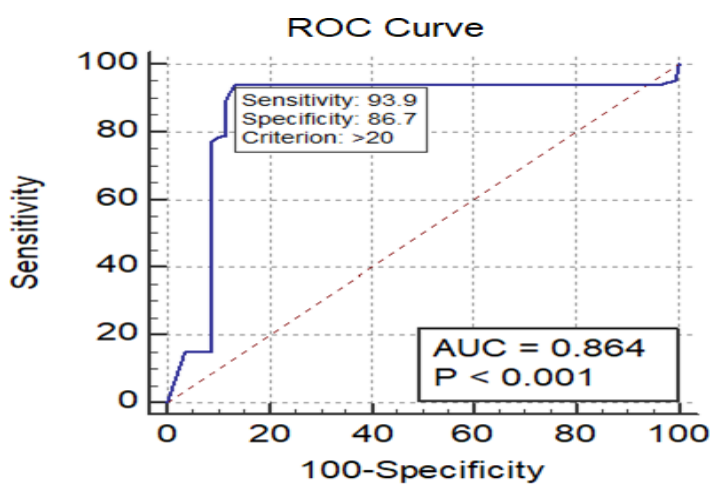

Biểu đồ 4. Biểu đồ ROC của thời gian với tăng chỉ số mõ nội tạng

Thời gian ăn chay có liên quan đến việc dự đoán tăng VFL với $\mathrm{p}<0,05$ và diện tích dưới đường cong là $86,4 \%$, tại điểm cắt trên 20 năm với độ nhạy $93,9 \%$, độ đặc hiệu $86,7 \%$.

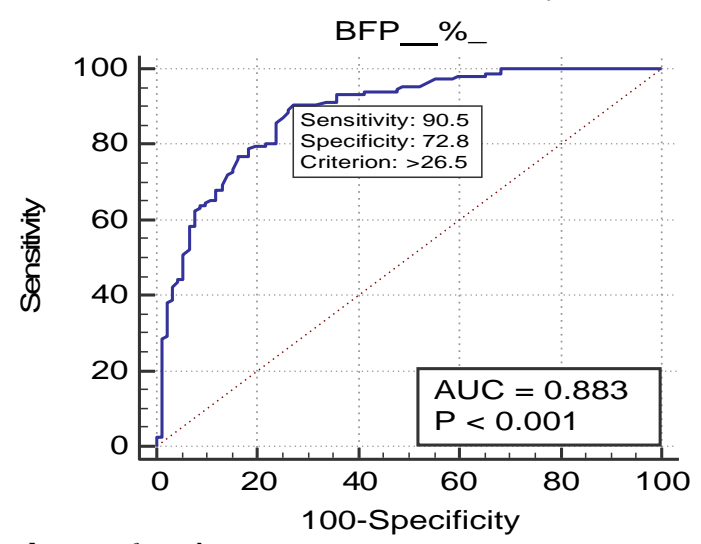

Biểu đồ 5. Biểu đồ ROC của BFP với chu vi vòng bụng $\geq 80 \mathrm{~cm}$

Chỉ số BFP có liên quan đến việc tăng chu vi vòng bụng $(\geq 80 \mathrm{~cm})$ với $\mathrm{p}<0,05$ và diện tích dưới đường cong là $88,3 \%$, tại điểm cắt trên $26,5 \%$ với độ nhạy $90,5 \%$, độ đặc hiệu $72,8 \%$. 


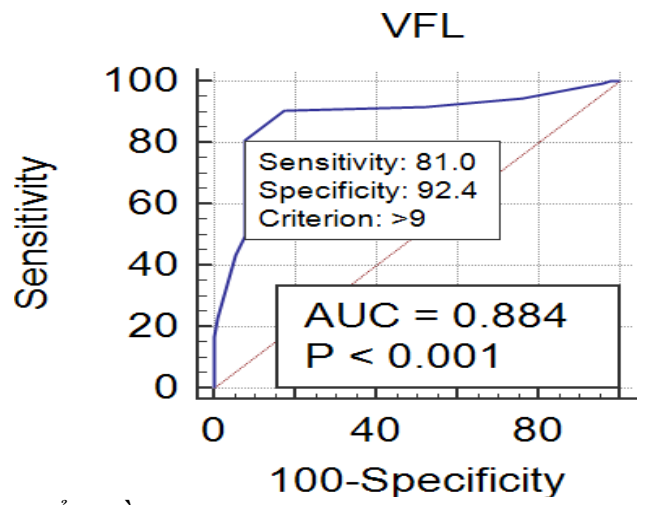

Biểu đồ 6. Biểu đồ ROC của VFL với chu vi vòng bung $\geq 80 \mathrm{~cm}$

Chỉ số $B F P$ có liên quan đến việc tăng chu vi vòng bụng $(\geq 80 \mathrm{~cm})$ với $\mathrm{p}<0,05$ và diện tích dưới đường cong là $88,4 \%$ tại điểm cắt $>9$ với độ nhạy $81,0 \%$, độ đặc hiệu $92,4 \%$.

\section{BÀN LUẬN}

Qua kết quả ở bảng 2 cho thấy ở nhóm phụ nữ ăn chay tỉ lệ mỡ cơ thể cao nhẹ và cao gấp 1,60 lần so với nhóm đối tượng không ăn chay $(\mathrm{p}<0,05)$. BFP từ mức cao nhẹ - cao chiếm $82,0 \%$, thì thấp hơn so với nghiên cứu Lê Thị Ngọc Lan (2013) là 85,2\%, Nguyễn Ngọc Tuấn (2015) là 96,9\%[2][4]. P.

Leelakumari (2017): tỷ lệ người ăn chay có chỉ số BFP cao hơn so với người không ăn chay $(74,5 \%-62,4 \%)$.

Kết quả bảng 3 ghi nhận ở nhóm phụ nữ ăn chay mức mỡ nội tạng cao nhẹ và cao gấp 1,55 lần so với nhóm đối tượng không ăn chay $(\mathrm{p}<0,05)$ mức mỡ nội tạng ở mức cao nhẹ-cao chiếm tỷ lệ $28,0 \%$ thấp hơn kết quả nghiên cứu Lê Thị Ngọc Lan là 34,3\% [2] nhưng cao hơn nghiên cứu của Nguyễn Ngọc Tuấn là $21,6 \%[4]$. Kết quả TLMCT và MMNT của chúng tôi có chênh lệch không nhiều so với các nghiên cứu trên có thể do đối tượng của các tác giả trên thực hiện trên các bệnh nhân có Hội chứng chuyển hóa $(n=168)$ và Thừa cân - Béo phì $(\mathrm{n}=41)$ [2],[4].

Kết quả của biểu đồ 2 , biểu đồ 2 chỉ ra BFP tương quan thuận trung bình với thời gian ăn chay $(r=0,437 ; p<0,05)$, VFL tương quan thuận với thời gian ăn chay $(\mathrm{r}=0,625$; $\mathrm{p}<0,05)$. Một số nghiên trước đây cũng ghi nhận BFP, VFL lần lượt có tương quan thuận với BMI, VB, HATT [2],[4].

Độ nhạy độ đặc hiệu của BFP và VFL:
Qua nghiên cứu chúng tôi ghi nhận độ nhạy việc phát hiện có $\mathrm{VB} \geq 80 \mathrm{~cm}$ bằng máy đo HBF-362 được ghi nhận ở biểu đồ là khá cao với $\mathrm{BFP}$ điểm cắt $26,5 \%$, độ nhạy $90,5 \%$, độ đặc hiệu $72,8 \%$ và $V F L$ với $V B \geq 80 \mathrm{~cm}$, điểm cắt 9 , độ nhạy $92,4 \%$, độ đặc hiệu $81,0 \%$ diện tích dưới đường cong ROC đều $>70 \%$. Theo tiêu chuẩn NCEP-ATP III $2001, \mathrm{VB} \geq 80 \mathrm{~cm}$ ở phụ nữ châu Á là 1 trong các tiêu chuẩn chần đoán bệnh lý $\mathrm{HCCH}$ [2].

\section{KẾT LUẬN}

- Chỉ số tỉ lệ mỡ cơ thể (BFP) có nguy cơ cao nhẹ và cao gấp 1,60 lần; chỉ số mức mỡ nội tạng (VFL) có nguy cơ cao nhẹ và cao gấp 1,60 lần ở phụ nữ ăn chay trường so với nhóm không ăn chay $(\mathrm{p}<0,05)$. Nhóm ăn chay tỷ lệ BFP cao nhẹ - cao chiếm $82,0 \%$, tỷ lệ VFL cao nhẹ - cao chiếm $28,0 \%$.

- Có sự tương quan thuận trung bình giữa $\mathrm{BFP}$ với thời gian ăn chay với phương trình hồi quy tuyến tính $\mathrm{y}=0,1969 \mathrm{x}+28,602$; $r=0,437 \quad(p<0,05)$. VFL tương quan thuận trung bình với thời gian ăn chay với phương trình hồi quy tuyến tính $\mathrm{y}=0,102 \mathrm{x}+0,3078$; $\mathrm{r}=0,625(\mathrm{p}<0,05)$. Tương quan hồi quy đa biến giữa VFL, BFP với thời gian ăn chay theo phương trình hồi quy đa biến: TGAC = $5,664+0,282 * \mathrm{BFP}+2,443 * \mathrm{VFL}$.

- Có dự đoán tăng BFP với thời gian ăn chay: tại điểm cắt 9 , độ nhạy $81,0 \%$, độ đặc hiệu $73,8 \%$ và dự đoán tăng VFL với thời 
gian ăn chay >20 năm (Se: 93,0\%, Sp:

$86,7 \%$ ).

- Tại điểm cắt, độ nhạy, độ đặc hiệu của $\operatorname{BFP}$ là $(26,5 \%, 90,5 \%, 72,8 \%)$ và của VFL là $(9 ; 92,4 \%, 81,0 \%)$ có liên quan đến dự đoán tăng vòng bụng $\geq 80 \mathrm{~cm}$.

\section{TÀI LIỆU THAM KHẢO}

1. Doãn Thị Tường Vi (2004), "Rối loạn lipid máu và tăng huyết áp ở người thừa cân", Hội nghị Khoa học toàn quốc, chuyên ngành "Nội tiêt và chuyển hóa", lần thứ hai.

2. Lê Thị Ngọc Lan (2013), Nghiên cứu tỷ lệ mỡ cơ thể và mức mỡ nội tạng ở bệnh nhân có hội chứng chuyển hóa, Luận án chuyên khoa cấp II, Trường Đại học Y Dược Huế.

3. Omron Viet Nam, (2013). "Tỉ lệ mỡ và mức mơ $n$ www.doctor100.vn/tu-van/kien-thuc-suckhoe-toan-dien.html.

4. Nguyễn Ngọc Tuấn (2015), "Nghiên cứu chỉ số mõ̃ cơ thể, mỡ tạng và mỡ dưới da ở bệnh nhân thừa cân béo phì", Luậnán chuyên khóa cấp II, Trường đại học Y Dược Huế.

5. Nguyễn Văn Tư (2005), Đặc điểm một số chỉ số sinh hóa, huyết học của người cao tuổi thừa cân béo phì tại thành phố Thái Nguyên", Y học thực hành (517) - số 8/2005.

6. Marc Perry, (2013), 5 ways to measure body fat percentage, www.builtlean.com/2010/07/13/.

7. Matsuzawa Y, Shimomura I, Nakamura T et al (1995), Pathophysiologyand pathogenesis of visceral fat obesity,Obes Res, $\quad 3 \quad$ Suppl 2, pp.187S-194S.

8. WHO (2000), "Obesity preventing and managing the gobal epidemic", Report of a WHO Colsultation on Obesity, series 894, pp. 174-183, 60-80.

9. P. Leelakumari(2017) Body Fat Percentage in a Vegetarian and NonVegetarian Population andPrevalence of Essential Hypertension and Type-2 Diabetes Mellitus: A Comparative Investigation in Indian PopulationInt $\mathbf{J}$ Med Res Prof.2017 Nov; 3(6); 9-12. 